\title{
Pulmonary Embolism in Sickle Cell Disease: A Case-Control Study
}

\author{
Enrico M. Novelli ${ }^{*}, 1,2,3$, Cindy Huynh ${ }^{*}, 1,2$, Mark T. Gladwin ${ }^{1,3,4}$, Charity G. Moore ${ }^{5}$, and \\ Margaret V. Ragni, MD, MPH ${ }^{1,2,3}$ [Professor] \\ ${ }^{1}$ Department of Medicine, Division Hematology/Oncology, University of Pittsburgh, PA, USA \\ ${ }^{2}$ Hemophilia Center of Western PA, Pittsburgh, PA, USA \\ ${ }^{3}$ Vascular Medicine Institute, University of Pittsburgh, PA, USA \\ ${ }^{4}$ Division of Pulmonary Medicine, University of Pittsburgh, PA, USA \\ ${ }^{5}$ Department of Medicine, Center for Research on Health Care Data Center, Pittsburgh, PA
}

\section{Summary}

Introduction-Pulmonary embolism (PE) is a leading cause of mortality in hospitalized patients, yet the prevalence of PE in sickle cell disease (SCD) and its relation to disease severity or intrinsic hypercoagulability are not established.

Methods-We estimated inpatient PE incidence and prevalence among SCD and non-SCD populations in Pennsylvania, and compared severity of illness and mortality, using Pennsylvania Health Care Cost Containment Council (PHC4) discharge data, 2001-2006. Risk factors for PE were assessed in a case-control study of discharges from the University of Pittsburgh Medical Archival Records System (MARS).

Results-The incidence of inpatient PE was higher in the SCD PA population than in the nonSCD Pennsylvania population, 2001-2006. The PE prevalence among SCD discharges $\mathbf{5 0}$ years of age, $0.57 \%$, was similar to that in non-SCD Pennsylvania discharges, $0.60 \%$, and unchanged after adjustment for race. Among SCD discharges, those developing PE were significantly older, with longer length ofstay, greater severity of illness, and higher mortality, $\mathrm{p}<0.001$, than SCD without PE. Among PE discharges, SCD had similar severity of illness, $\mathrm{p}=0.77$, and mortality, $\mathrm{p}=0.39$, but underwent fewer computerized tomographic scans, $\mathrm{p}=0.006$, than non-SCD with PE. In the local case-control study, no clinical or laboratory feature was associated with PE.

Conclusions-The incidence of PE is higher and chest CT utilization is lower in SCD than nonSCD inpatients, suggesting that PE may be under-diagnosed.

\footnotetext{
Reprint Address: Margaret V. Ragni, MD, MPH Professor of Medicine and Clinical \& Translational Science Division Hematology/ Oncology University of Pittsburgh Medical Center Director, Hemophilia Center of Western PA 3636 Boulevard of the Allies, Pittsburgh, Pennsylvania 15213-4306 Telephone: 412-209-7288 Fax: 412-209-7281 ragni@pitt.edu.

* shared equally as first authors.

Addendum

M.V.R. and C.G.M. designed the research. E.M.N. and C.H. performed the research, C.H. collected the data, and E.M.N. reviewed cases for accuracy and completeness, and verified identification of cases and controls. C.G.M. performed the statistical analysis. M.V.R, E.M.N., C.H., and M.T.G. analyzed the data and formulated the conclusions. E.M.N., C.H. and M.V.R. wrote the paper. E.M.N. and C.H. shared equally as first authors.

Conflict of interest

The authors declare no competing financial interests.
} 


\section{Keywords}

Pulmonary embolism; sickle cell disease; venous thromboembolism

\section{Introduction}

Although thrombosis has been recognized as a complication of sickle cell trait [1], and coagulation and platelet activation are present even in the non-crisis state [2], the rates of thrombosis are not established in sickle cell disease (SCD). In a study of hospitalized SCD patients, the prevalence of pulmonary embolism (PE) was 3.5 fold higher than in agematched non-SCD African Americans, although the prevalence of deep venous thrombosis (DVT) was not increased [3]. Thrombosis is an important clinical issue in SCD, as it may be driven not only by coagulation and platelet activation, but also by hemolysis-associated endothelial dysfunction $[2,4-6]$. Pulmonary emboli may contribute to pulmonary symptoms associated with acute chest syndrome and pulmonary hypertension [7], and while identified in up to $50 \%$ of autopsied SCD cases $[8,9]$, are detected clinically in only $5 \%$ of cases [10-12], in part because they are difficult to distinguish from in situ thrombosis [12, 13]. Further, although PE are not thought to cause acute chest syndrome [14], they are considered a leading cause of death in those with acute chest syndrome [7-12, 15]. Pulmonary artery thrombosis has also been detected in up to $17 \%$ of those hospitalized with acute chest syndrome (ACS), particularly in those with higher platelet counts [16], suggesting that PE in SCD may actually represent thrombi formed in the pulmonary arteries rather than embolic events from distal venous circulation. Despite these findings, the role of anticoagulation in SCD is not established. Among hospitalized patients, PE accounts for $10 \%$ of deaths [7], for which prophylactic anticoagulation guidelines have been recommended [17], yet the impact of anticoagulation on health outcomes in SCD patients, who are frequently hospitalized, has not been thoroughly studied, and prophylactic anticoagulation is not routinely prescribed in hospitalized SCD patients. Small clinical trials have demonstrated benefit of anticoagulation on painful crisis and pain scores [18-22], but few data address the impact of anticoagulation on thrombosis prevention. We determined the incidence and prevalence of pulmonary embolism by analyzing Pennsylvania state inpatient discharge data (2001-2006) by age, gender, race, diagnostic procedures, and severity of illness, comparing SCD patients developing PE, SCD patients not developing PE, and nonSCD patients developing PE.

\section{Materials and Methods}

Inpatient hospital discharge data for pulmonary embolism for the most recent 5-year period available, 2001-2006, were obtained from the Pennsylvania Health Care Cost containment Council (PHC4). The PHC4 is an independent agency that collects inpatient hospital discharge and ambulatory/ outpatient procedure records from hospitals and ambulatory surgery centers in Pennsylvania to assess health care costs [23]. We compared age, race and sex, co-morbidity, procedures, mortality, and Atlas severity of illness in SCD discharges with and without PE and non-SCD discharges without PE by analyzing PHC4 statewide discharge data between 2001 and 2006. All patient identifiers were removed. SCD was defined by ICD-9 codes for HbSS, HbSC, HbS/thal, and HbAS (sickle trait) (codes 282.60; $282.61 ; 282.62 ; 282.63 ; 282.64 ; 282.68$; and 282.69) [24]. PE discharges were identified using ICD-9 codes 512.11 and 415.19. Pregnant patients and all second or later admissions for PE were excluded from analysis. Pennsylvania population figures were obtained from the U.S. Census Bureau [25]. Estimates of Pennsylvania adults affected by SCD were based on Pennsylvania state department of health data [26], U.S. state-specific SCD prevalence data [27], and physician estimates [28]. Diagnostic procedures were identified using revenue 
codes for CT (including spiral CT) scans. Clinical data, including height, weight, type of crisis, severity of crisis based on hemoglobin, reticulocytes, white blood cells, platelets, and $\mathrm{HbF}$ were analyzed. Co-morbidities were also collected, including trauma and congestive heart failure.

Data not available in the PHC4 database, including co-morbidities, medications, red blood cell transfusions, laboratory measures, and pain crises, were obtained on all available SCD with PE and SCD without PE inpatients at University of Pittsburgh Medical Center (UPMC) during the same time period, using the same ICD-9 codes, from the Medical Archival Record System (MARS) database, by an honest broker. Co-morbidities included pneumonia, stroke, acute coronary syndrome, and fractures; and confounders included hypertension, smoking, hypercholesterolemia, diabetes, HIV infection, and body mass index (BMI). Procedures included all computerized tomographic (CT) scans, spiral CT scans, chest roentgenograms (CXR), arterial blood gases (ABG), electrocardiograms (EKG), echocardiograms (ECHO); and laboratory findings included hemoglobin, reticulocytes, white blood cells, platelets, and d-dimer assay. Specific medications included hydroxyurea, iron chelating agents, anticoagulation agents including enoxaparin, warfarin, and unfractionated heparin. Subset SCD patients with PE (cases) were matched to SCD patients without PE (controls) in the MARS system by age within five years, race, gender, and year of admission. For the local dataset (MARS database), all SCD cases with PE were verified independently by E.M.N., the physician caring for the patients. The CT and V/Q scans of these patients were also independently verified for each of the local SCD with PE and SCD without PE patients to verify any PE diagnoses that had not been previously coded: none were detected.

Data from categorical variables were analyzed using frequencies and percentages to describe the distributions of the variables for all SCD patients and by PE status. Percentages were compared across groups by SCD and PE status by chi-square and Fisher's exact test. Data from continuous measures were summarized using, means and standard deviations, and comparisons were by two-sample Student's t-test.

\section{Results}

The PE incidence between 2001 and 2006 was 50-100-fold higher in the SCD population than in the general Pennsylvania population (Table 1). SCD PE incidence is based on the total number of SCD patients in PA, which is an estimate, although with good agreement among cited sources [26-28]. By contrast, the prevalence of PE among SCD admissions over the period, $0.57 \%$, was similar to the proportion of PE among non-SCD PE admissions, $0.60 \%$, increasing about 1.5 -fold over the period in both the SCD and non-SCD groups, $0.51 \%$ to $0.72 \%$, and from $0.49 \%$ to $0.72 \%$, respectively (Table 1 ). SCD PE prevalence is based on the annual rate of SCD admissions, and, thus, may reflect the higher annual rate of SCD than non-SCD admissions. The prevalence of PE among African-American SCD admissions over the period, $0.58 \%$, was similar to the prevalence of PE among AfricanAmerican non-SCD admissions, $0.59 \%$.

Compared with non-SCD admissions with PE 50 years of age, SCD admissions with PE had similar Atlas severity of illness scores, $8.1 \%$ vs. $7.7 \%$ in the two highest categories, $\mathrm{p}=0.77$, and mortality, $6.2 \%$ vs. $4.2 \%, \mathrm{p}=0.39$, but underwent fewer CT scans, $42.0 \%$ vs. $57.2 \%, \mathrm{p}=0.006$ (Table 2). Comparing to inpatient African-Americans only, the rate of CT scans was similar, $42.0 \%$ vs. $46.0 \%, \mathrm{p}=0.48$. SCD admissions with PE were older, 37.0 vs. 28.0 years, $\mathrm{p}<0.0001$, had a longer length of stay, 9.2 vs. 5.0 days, $\mathrm{p}<0.0001$, greater Atlas severity of illness, $8.1 \%$ vs. $3.3 \%$ in the two highest categories, $\mathrm{p}<0.0001$, and higher inpatient mortality, $6.2 \%$ vs. $1.4 \%$, $\mathrm{p}=0.0006$, than SCD admissions without PE. Further, 
SCD admission with PE were more likely to undergo imaging studies, including CT scan, $42.0 \%$ vs. $9.6 \%, \mathrm{p}=0.0001$, than SCD without PE (Table 2 ).

Analysis of a local University of Pittsburgh sample revealed no distinguishing clinical features associated with PE (Table 3). The data confirmed the longer length of stay and greater use of CT scans among hospitalized SCD with PE as compared with hospitalized SCD without PE. Comorbidities were no greater in cases than controls, nor were risk factors for thrombosis, including diabetes, hypertension, obesity, smoking, hyperlipidemia, coronary symptoms, HIV, or HCV. There were also no differences in the sickle cell genotype, i.e. HbSS, HbSC, HbS/thal, or HbAS (sickle trait), $\mathrm{p}=0.861$, type of crisis, $\mathrm{p}=0.895$, laboratory parameters, transfusions, or iron chelation therapy. As expected, all of those SCD with PE received anticoagulation, but only $15 \%$ of hospitalized SCD without PE did, $\mathrm{p}<0.001$.

\section{Discussion}

Utilizing a large discharge database from the state of Pennsylvania, this study establishes the higher incidence of PE in individuals with SCD than in non-SCD individuals on a year-byyear basis. PE prevalence among hospitalized SCD patients was comparable to non-SCD patients, even after adjusting for age and race. There was similar severity of illness and mortality, but proportionately fewer CT scans were performed in SCD discharges with PE than non-SCD discharges with PE.

Pulmonary embolism may go unrecognized in SCD patients, including in $17 \%$ of acute chest syndrome (ACS) who develop PE [16] and in up to 90\% who die of PE [29]. Given the 6\% mortality rate we found among SCD with $\mathrm{PE}$, which is at least 4-fold greater than that among SCD without PE, and the evolving refinement of chest CT technology with potential for earlier PE detection [23], consideration should be given to a higher index of suspicion and a lower threshold for performing chest CT pulmonary angiography [30] in SCD patients, particularly in those with pulmonary symptoms. Prospective clinical studies will be needed to confirm the utility of this approach.

Although all SCD with PE subjects received anticoagulation, fewer than $15 \%$ of hospitalized SCD without PE received anticoagulation. The latter is consistent with published VTE prophylaxis practices in this group [31, 32] and consistent with Chest 2012 recommendations for anticoagulant thromboprophylaxis in hospitalized patients at increased risk of thrombosis who are not bleeding or at high risk for bleeding [33]. While anticoagulation trials in SCD patients have shown variable results [18-22], SCD-related rather than thrombosis-related outcomes were assessed, and, thus, whether anticoagulation is safe in SCD remains unanswered. However, the absence of bleeding or hematologic differences between groups suggests there may be no increased risk. In the absence of clear contraindication to VTE prophylaxis, and given our finding that PE prevalence is at least as common in hospitalized SCD as in hospitalized non-SCD patients, prophylactic anticoagulation should be considered in all SCD inpatients, and clinical trials initiated to determine the safety and efficacy of prophylactic anticoagulation in hospitalized SCD patients.

No distinguishing clinical or laboratory parameter was found to be predictive of PE in this study. This may relate to the small sample of subjects in our MARS system, suggesting the need for prospective studies with more accurate VTE detection, e.g. via CT pulmonary angiography, and with better VTE prediction biomarkers, e.g. rate of hemolysis, von Willebrand factor levels, platelet activation, and cytokines [2, 29, 31, 32]. 
There are a number of limitations of this study. First, the incidence of PE in SCD patients in Pennsylvania is likely to be an underestimate as only hospitalized Pennsylvania patients are included, excluding non-Pennsylvania residents, Pennsylvania residents admitted in other states, or those who die before admission. Further, chest CT appears to be under-utilized in SCD patients, whose signs and symptoms may mimic PE. Second, the power of the casecontrol study to identify predictors of PE among SCD patients may be limited by the small number of local subjects with SCD identified in the MARS database. Third, there is the possibility of ascertainment bias, that is, SCD patients who present with a primary diagnosis of sickle cell crisis may not have been coded with a second diagnosis of PE, a potential limitation of using ICD-9 codes to identify patients for inclusion in this study. It should be noted, however, that all local cases were independently verified by their physician, E.M.N., and independent review of all pulmonary tomographic scans revealed that no cases were incorrectly identified. Fourth, it was not possible to determine the cause of PE in this study, as the PHC4 database does not distinguish whether PE was the admitting diagnosis or subsequent diagnosis. Finally, although a diagnosis of sickle trait was included within the study definition for SCD, it should be noted that many with sickle trait may be unaware of their status, and, thus these data could lead to erroneous conclusions about its role as a possible risk factor for PE.

Despite these limitations, the study has some major strengths. The use of Pennsylvania discharge data and US census population data for the state provided the opportunity to determine the incidence of PE in hospitalized SCD and to demonstrate that PE prevalence is similar between hospitalized SCD and non-SCD patients. The fact that proportionately fewer SCD undergo diagnostic CT scans and only a minority receives prophylactic anticoagulation suggests the need for heightened suspicion, earlier detection, and clinical trials to determine whether prophylactic anticoagulation in hospitalized SCD patients is warranted.

\section{Acknowledgments}

We acknowledge the work of the honest broker, Ms. Melissa Saul, University of Pittsburgh. The study was supported by HHS Federal Region III Hemophilia Treatment Centers, Grant \#1-H-30-MC-0038-01; the Centers for Diseases Control Prevention of Complications of Hemophilia Grant U10DD000193; the Pennsylvania Department of Health State SAP \#04100000330; and CTRC/CTSI NIH NCRR/CTSA UL-1 RR024153

\section{References}

1. Austin H, Key NS, Benson JM, Lally C, Dowling NF, Whitsett C, Hooper WC. Sickle cell trait and the risk of venous thromboembolism among blacks. Blood. 2007; 110:908-912. [PubMed: 17409269]

2. Villagra J, Shiva S, Hunter LA, Machado RF, Gladwin MT, Kato GJ. Platelet activation in patients with sickle disease, hemolysis-associated pulmonary hypertension, and nitric oxide scavenging by cell-free hemoglobin. Blood. 2007; 110:2166-2172. [PubMed: 17536019]

3. Stein PD, Beemath A, Meyers FA, Skaf E, Olson RE. Deep venous thrombosis and pulmonary embolism in hospitalized patients with sickle cell disease. Am J Med. 2006; 119:897, e7-e11. [PubMed: 17000225]

4. Gladwin MT, Vichinsky E. Pulmonary complications of sickle cell disease. N Engl J Med. 2008; 359:2254-2265. [PubMed: 19020327]

5. Hu W, Jin R, Zhang J, You T, Peng Z, Ge X, Bronson RT, Halperin JA, Loscalzo J, Qin X. The critical roles of platelet activation and reduced NO bioavailability in fatal pulmonary arterial hypertension in a murine hemolysis model. Blood. 2010; 116:1613-1622. [PubMed: 20511540]

6. Vichinsky EP, Styles LA, Colangelo LH, Wright EC, Castro O, Nickerson B. Acute chest syndrome in sickle cell disease: clinical presentation and course. Blood. 1997; 89:1787-1792. [PubMed: 9057664] 
7. Vichinsky EP, Neumayr LD, Earles AN, Williams R, Lennette ET, Dean D, Nickerson B, Orringer E, McKie V, Bellevue R, Daeschner C, Manci EA, for the National Acute Chest Syndrome Study Group. Causes and outcomes of the acute chest syndrome in sickle cell disease. N Engl J Med. 2000; 342:1855-1865. [PubMed: 10861320]

8. Manci EA, Culberson DE, Yang YM, Gardner TM, Powell R, Haynes J, Shah AK, Mankad VN. Causes of death in sickle cell disease: an autopsy study. Br J Haematol. 2003; 123:359-365. [PubMed: 14531921]

9. Lindblad B, Eriksson A, Bergqvist D. Autopsy-verified pulmonary embolism in a surgical department: analysis of the period from 1951 to 1988. Br J Surg. 1991; 78:849-852. [PubMed: 1873716]

10. Oppenheimer EH, Esterly JR. Pulmonary changes in sickle cell disease. Am Rev Respir Dis. 1971; 103:858-9. [PubMed: 5089881]

11. Aliyu ZY, Kato GJ, Taylor J, Babadoko A, Mamman AI, Gordeuk VR, Gladwin MT. Sickle cell disease and pulmonary hypertension in Africa: a global perspective and review of epidemiology, pathophysiology, and management. Am J Hematol. 2008; 83:63-70. [PubMed: 17910044]

12. Walker BK, Ballas SK, Burka ER. The diagnosis of pulmonary thromboembolism in sickle cell disease. Am J Hematol. 1979; 7:219-232. [PubMed: 547737]

13. Maggi JC, Nussbaum E. Massive pulmonary infarction in sickle cell anemia. Pediatr Emerg Care. 1987; 3:30-32. [PubMed: 3562309]

14. Kirkpatrick MB, Haynes J. Sickle cell disease and the pulmonary circulation. Semin Resp Crit Care Med. 1994; 15:473-481.

15. Rubler S, Fleisher RA. Sickle cell states and cardiomyopathy. Sudden death due to pulmonary thrombosis and infarction. Am J Cardiol. 1967; 19:867-873. [PubMed: 6026153]

16. Dessap AM, Deux JF, Abidi N, Lavenu-Bombled C, Melica G, Renaud B, Godeau B, Adnot S, Brochard L, Brun-Buisson C, Galacteros F, Rahmouni A, Habibi A, Maitre B. Pulmonary artery thrombosis during acute chest syndrome in sickle cell disease. Am J Respir Crit Care Med. 2011; 184:1022-9. [PubMed: 21836136]

17. Kearon C, Kahn SR, Agnelli G, Goldhaber S, Raskob GE, Comerota AJ. Antithrombotic therapy for venous thromboembolic disease: American College of Chest Physicians Evidence-Based Clinical practice guidelines ( ${ }^{\text {th }}$ Edition). Chest. 2008; 133:454S-545S. [PubMed: 18574272]

18. Qari MH, Aljaouni SK, ALardawi MS, Fatani H, Alsayes FM, Zografos P, Alsaigh M, Alalfi A, Alamin M, Gadi A, Mousa SA. Reduction of painful vaso-occlusive crisis of sickle cell anemia by tinzaparin in a double-blind randomized trial. Thromb Haemost. 2007; 98:392-96. [PubMed: 17721622]

19. Salvaggio JE, Arnold CA, Banov CH. Long-term anticoagulation in sickle cell disease. N Engl J Med. 1963; 269:182-6. [PubMed: 13991207]

20. Wolters HJ, ten Cate H, Thormas LL, Brandjes DP, van der Ende A, van der Heide Y, van Epps LW. Low-intensity oral anticoagulation in sickle cell disease reverses the prethrombotic state: promises for treatment? Br J Hematol. 1995; 90:715-717.

21. Schnog JB, Kater AP, MacGillavry MR, Duits AJ, Lard LR, van der Dijs FP, Brandjes DP, ten Cate J, van Eps LW, Rojer RA. Low adjusted dose acenocoumarol therapy in sickle cell disease; a pilot study. Am J Haematol. 2001; 68:179-183.

22. Chaplin H, Monroe MC, Malecek AC, Morgan LK, Michael J, Murphy WA. Preliminary trial of minidose heparin prophylaxis for painful sickle cell crises. East Afri Med J. 1989; 66:574-584.

23. Pennsylvania Health Care Cost Containment Council. [July 20, 2010] About the Council. http://www.phc4.org/council/mission.htm.

24. 2009 ICD-9-CM Volume 1 Diagnosis Codes, International Classification of Diseases. http://www.icd9data.com/2009/Volume1/htm

25. U.S. Census Bureau national and state population estimates. [July 20, 2011] http://www.census.gov/popest/estimates.php.

26. Personal communication, Ms. Judith Good, Pennsylvania Health Care Cost Containment Council, January 20, 2012.

27. Hassell KL. Population estimates of sickle cell disease in the U.S. Am J Prev Med. 2010; 38(4S):S512-S521. [PubMed: 20331952] 
28. Personal communication, Dr. Lakshmanan Krishnamurti, Children's Hospital of Pittsburgh, January 23, 2012.

29. Chen J, Hobbs WE, Le J, Lenting PJ, de Groot PG, Lopez JA. The rate of hemolysis in sickle cell disease correlates with the quantity of active von Willebrand factor in the plasma. Blood. 2011; 117:3680-3683. [PubMed: 21300978]

30. DeMonaco NA, Dang Q, Kapoor WN, Ragni MV. Pulmonary embolism incidence is increasing with use of spiral computed tomography. Am J Med. 2008; 121:611-617. [PubMed: 18589057]

31. Tapson VF. Acute pulmonary embolism. N Engl J Med. 2008; 358:1037-1052. [PubMed: 18322285]

32. Cohen AT, Tapson VF, Bergmann JF, Goldhaber SZ, Kakkar AK, Deslandes B, Huang W, Zayaruzny M, Emery L, Anderson FA. Venous thromboembolism risk and prophylaxis in the acute hospital care setting (ENDORSE study): a multi-national cross-sectional study. Lancet. 2008; 371:387-394. [PubMed: 18242412]

33. Kahn SR, Lim W, Dunn AS, Cushman M, Dentali F, Akl EA, Cook DJ, Balekian AA, Klein RC, Le H, Schulman S, Murad MH. Prevention of VTE in nonsurgical patients: Antithrombotic Therapy and Prevention of Thrombosis, $9^{\text {th }}$ ed: American College of Chest Physicians evidencebased clinical practice guidelines. Chest. 2012; 1412(Suppl):e195S-226S. [PubMed: 22315261] 


\begin{tabular}{|c|c|c|c|c|c|c|c|c|c|}
\hline 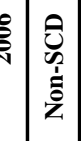 & $\mid \begin{array}{c}\stackrel{\partial}{े} \\
\text { ( }\end{array}$ & 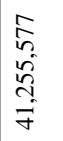 & $\mid \begin{array}{c}\circ \\
\infty \\
o \\
O \\
0 \\
0\end{array}$ & 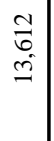 & $\begin{array}{l}\stackrel{0}{9} \\
\stackrel{-}{-} \\
\infty \\
\infty \\
- \\
-\end{array}$ & $\begin{array}{l}0 \\
\stackrel{2}{0} \\
0\end{array}$ & 氮 & 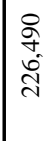 & $\begin{array}{l}\stackrel{\circ}{\circ} \\
\stackrel{0}{0}\end{array}$ \\
\hline ర్లి & $\vec{\sim}$ & 字 & 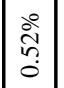 & 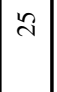 & 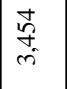 & 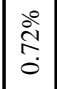 & $\approx$ & స్స & 0 \\
\hline
\end{tabular}

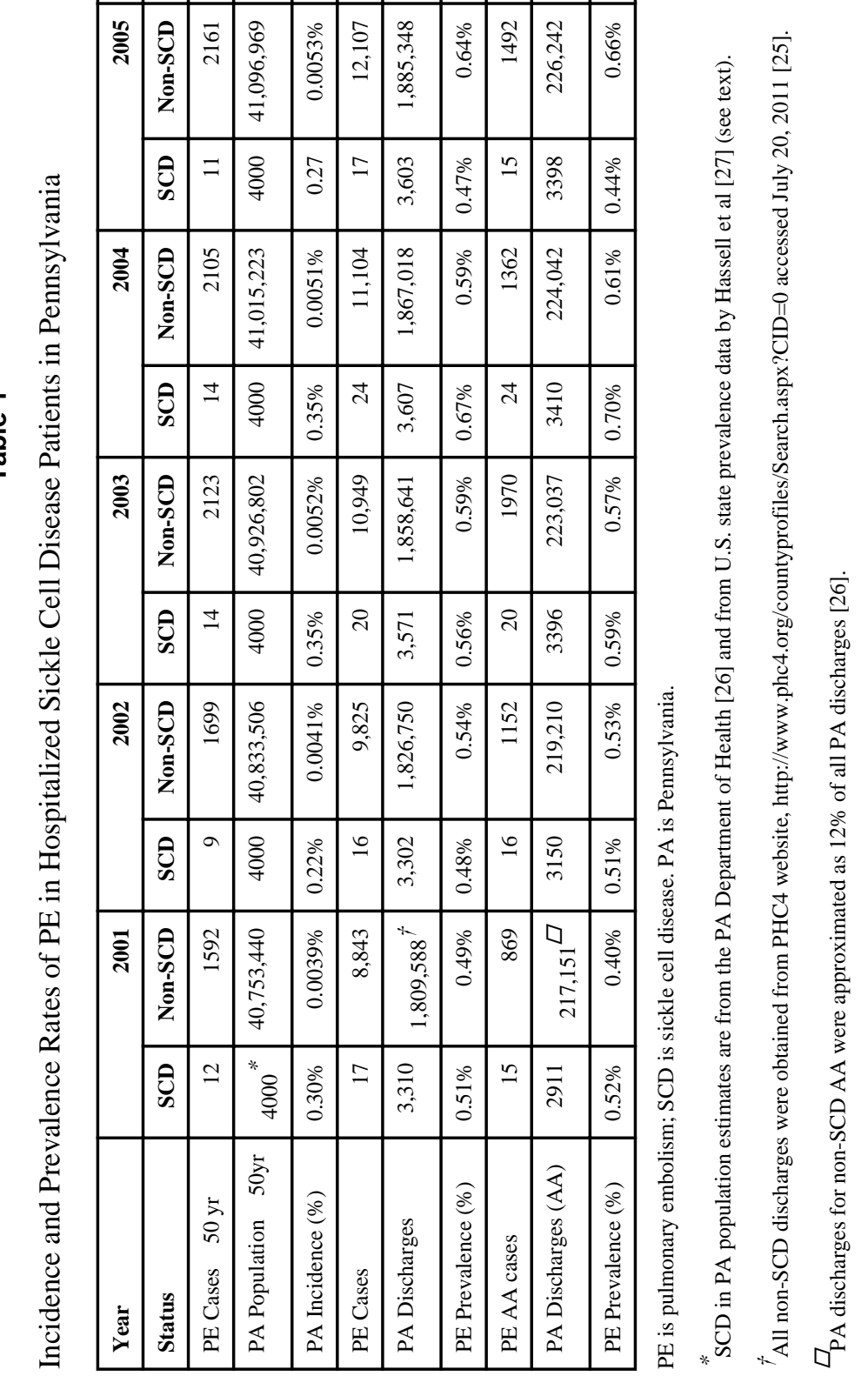

衰

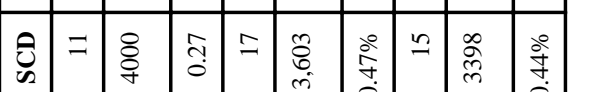

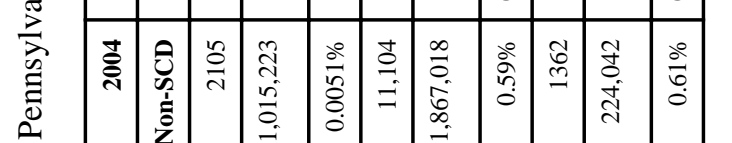

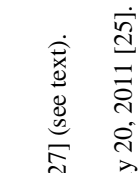




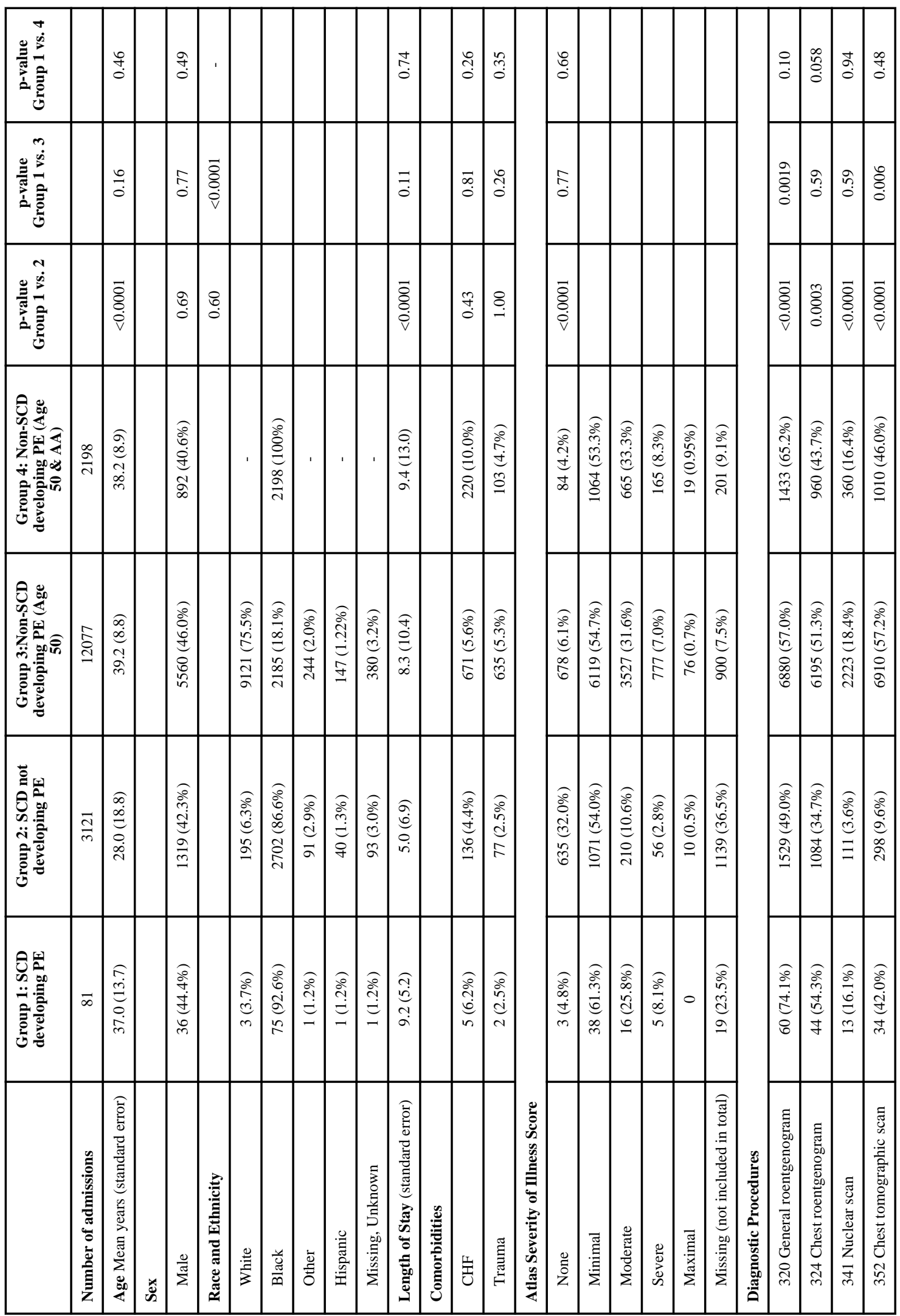




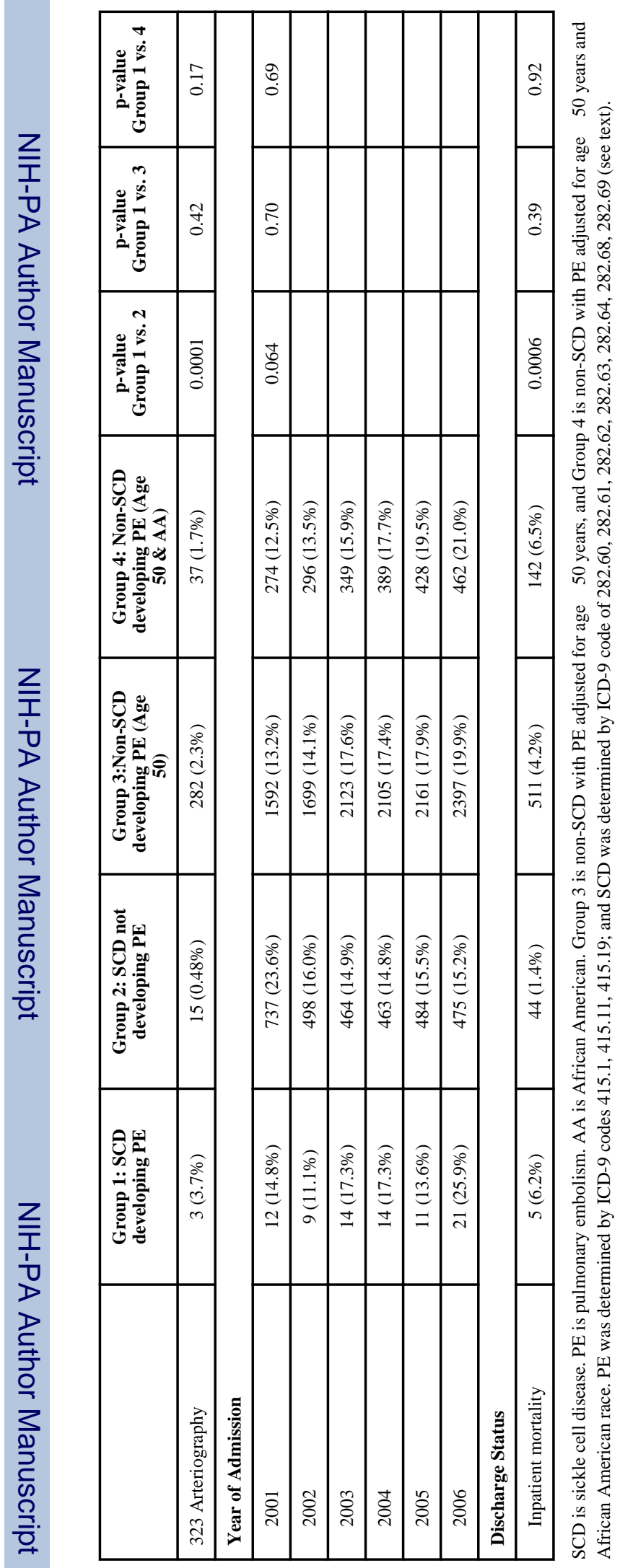

J Thromb Haemost. Author manuscript; available in PMC 2013 May 01. 


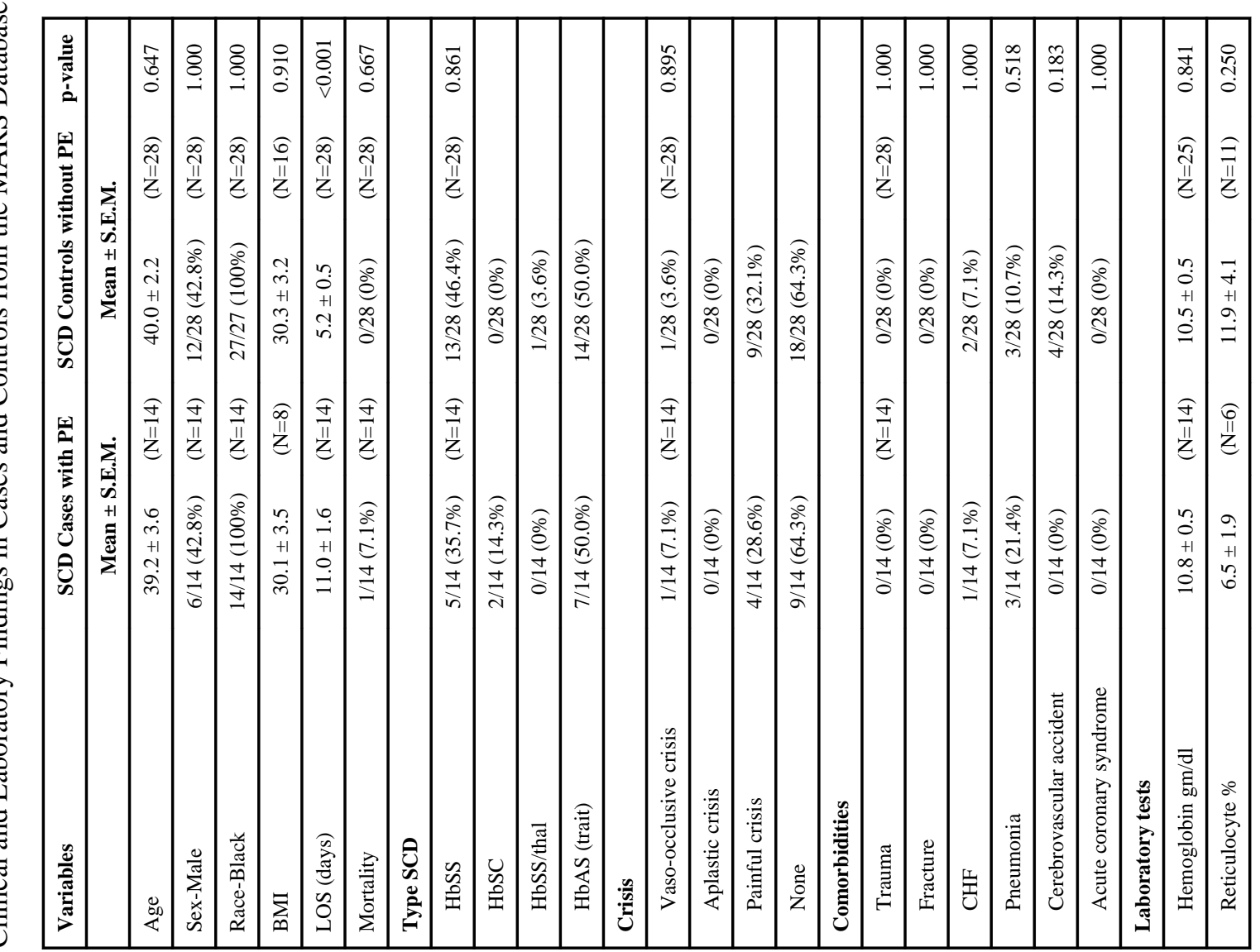




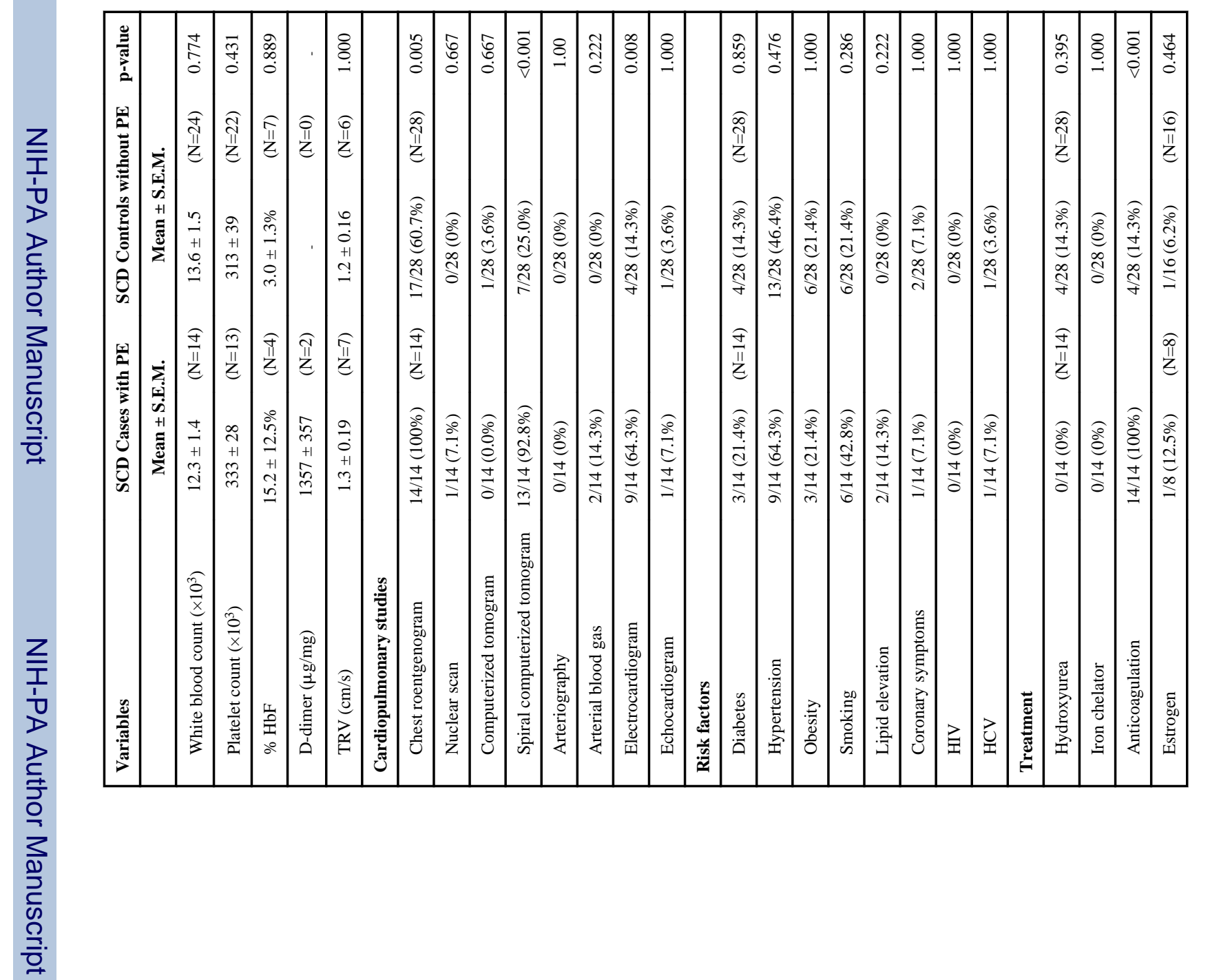

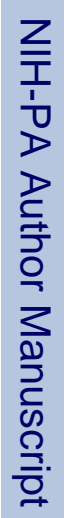




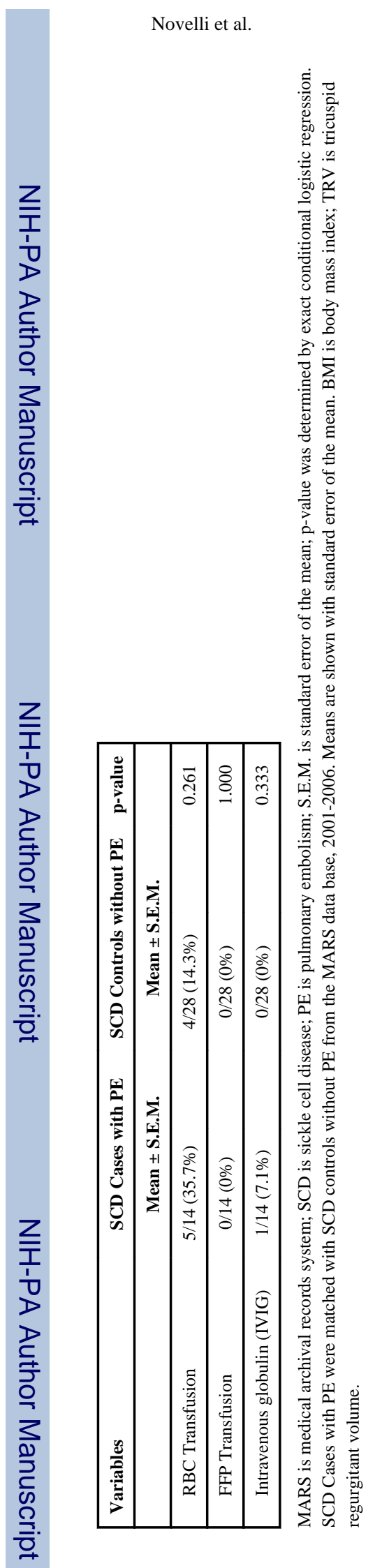

Page 13 